\title{
An Observational, Prospective, Multicenter, Registry-Based Cohort Study Comparing Conservative and Medical Management for Patent Ductus Arteriosus
}

OPEN ACCESS

Edited by:

Vineet Bhandari,

Cooper University Hospital,

United States

Reviewed by:

Jonathan Slaughter.

Nationwide Children's Hospital, United States

Erik Allen Jensen,

Children's Hospital of Philadelphia,

United States

*Correspondence:

Omer Erdeve

omererdeve@yahoo.com

Specialty section:

This article was submitted to

Neonatology,

a section of the journal

Frontiers in Pediatrics

Received: 02 April 2020 Accepted: 22 June 2020

Published: 31 July 2020

Citation:

Okulu E, Erdeve O, Arslan Z, Demirel N, Kaya H, Gokce IK, Ertugrul S, Cetinkaya M, Buyukkale G, Ozlu F, Simsek H, Celik Y, Ozkan H, Köksal N,

Akcan B, Turkmen M, Celik K

Armangil D, Bulbul A, Tekgunduz KS,

Oncel MY, Tuzun F, Ergenekon E, Ergin

$H$, Arsan S and Turkish Neonatal

Society INTERPDA Study Group (2020) An Observational, Prospective,

Multicenter, Registry-Based Cohort

Study Comparing Conservative and

Medical Management for Patent

Ductus Arteriosus.

Front. Pediatr. 8:434.

doi: 10.3389/fped.2020.00434
Emel Okulu ${ }^{1}$, Omer Erdeve ${ }^{1 *}$, Zehra Arslan ${ }^{2}$, Nihal Demirel $^{3}$, Huseyin Kaya $^{4}$, Ismail Kursad Gokce ${ }^{4}$, Sabahattin Ertugrul ${ }^{5}$, Merih Cetinkaya ${ }^{6}$, Gokhan Buyukkale ${ }^{6}$, Ferda Ozlu ${ }^{7}$, Huseyin Simsek ${ }^{7}$, Yalcin Celik ${ }^{8}$, Hilal Ozkan $^{9}$, Nilgun Köksal $^{9}$, Baris Akcan $^{10}$, Munevver Turkmen ${ }^{10}$, Kiymet Celik ${ }^{11}$, Didem Armangil ${ }^{12}$, Ali Bulbul ${ }^{13}$, Kadir Serafettin Tekgunduz ${ }^{14}$, Mehmet Yekta Oncel ${ }^{15}$, Funda Tuzun ${ }^{16}$, Ebru Ergenekon ${ }^{17}$, Hacer Ergin ${ }^{18}$, Saadet Arsan ${ }^{1}$ and Turkish Neonatal Society INTERPDA Study Group

${ }^{1}$ Division of Neonatology, Department of Pediatrics, Ankara University School of Medicine, Ankara, Turkey, ${ }^{2}$ Department of Neonatology, Etlik Zubeyde Hanim Women's Health Teaching and Research Hospital, University of Health Sciences, Ankara, Turkey, ${ }^{3}$ Division of Neonatology, Department of Pediatrics, Ankara Yildirim Beyazit University School of Medicine, Ankara, Turkey, ${ }^{4}$ Division of Neonatology, Department of Pediatrics, Inonu University School of Medicine, Malatya, Turkey, ${ }^{5}$ Division of Neonatology, Department of Pediatrics, Dicle University School of Medicine, Diyarbakir, Turkey, ${ }^{6}$ Department of Neonatology, University of Health Sciences, Kanuni Sultan Suleyman Training and Research Hospital, Istanbul, Turkey, ${ }^{7}$ Division of Neonatology, Department of Pediatrics, Cukurova University School of Medicine, Adana, Turkey, ${ }^{8}$ Division of Neonatology, Department of Pediatrics, Mersin University School of Medicine, Mersin, Turkey, ${ }^{9}$ Division of Neonatology, Department of Pediatrics, Uludag University School of Medicine, Bursa, Turkey, ${ }^{10}$ Division of Neonatology, Department of Pediatrics, Adnan Menderes University School of Medicine, Aydin, Turkey, ${ }^{11}$ Neonatal Intensive Care Unit, Diyarbakir Gazi Yasargil Training and Research Hospital, Diyarbakir, Turkey, ${ }^{12}$ Neonatal Intensive Care Unit, Koru Hospital, Ankara, Turkey, ${ }^{13}$ Department of Neonatology, University of Health Sciences, Sisli Etfal Hamidiye Training and Research Hospital, Istanbul, Turkey, ${ }^{14}$ Division of Neonatology, Department of Pediatrics, Ataturk University School of Medicine, Erzurum, Turkey, ${ }^{15}$ Division of Neonatology, Department of Pediatrics, Izmir Katip Celebi University School of Medicine, Izmir, Turkey, ${ }^{16}$ Division of Neonatology, Department of Pediatrics, Dokuz Eylul University School of Medicine, Izmir, Turkey, ${ }^{17}$ Division of Neonatology, Department of Pediatrics, Gazi University School of Medicine, Ankara, Turkey, ${ }^{18}$ Division of Neonatology, Department of Pediatrics,

Pamukkale University School of Medicine, Denizli, Turkey

No consensus has been reached on which patent ductus arteriosus (PDAs) in preterm infants require treatment and if so, how, and when they should be treated. A prospective, multicenter, cohort study was conducted to compare the effects of conservative approaches and medical treatment options on ductal closure at discharge, surgical ligation, prematurity-related morbidities, and mortality. Infants between 240/7 and 286/7 weeks of gestation from 24 neonatal intensive care units were enrolled. Data on PDA management and patients' clinical characteristics were recorded prospectively. Patients with moderate-to-large PDA were compared. Among the 1,193 enrolled infants (26.7 \pm 1.4 weeks and $926 \pm 243 \mathrm{~g}), 649$ (54\%) had no or small PDA, whereas 544 (46\%) had moderate-to-large PDA. One hundred thirty (24\%) infants with moderate-to-large PDA were managed conservatively, in contrast to 414 (76\%) who received medical treatment. Eighty (62\%) of 130 infants who were managed conservatively did not receive any rescue treatment and the PDA closure rate was 53\% at discharge. There were no 
differences in the rates of late-onset sepsis, necrotizing enterocolitis (NEC), retinopathy of prematurity, intraventricular hemorrhage ( $\geq$ Grade 3 ), surgical ligation, and presence of PDA at discharge between conservatively-managed and medically-treated infants $(p>0.05)$. Multivariate analysis including perinatal factors showed that medical treatment was associated with increased risk for mortality (OR 1.68, 95\% Cl 1.01-2.80, $p=0.046$ ), but decreased risk for BPD or death (BPD/death) (OR 0.59, 95\% Cl $0.37-0.92, p=0.022$ ). The preferred treatment options were ibuprofen (intravenous $36 \%$, oral $31 \%$ ), and paracetamol (intravenous $26 \%$, oral $7 \%$ ). Infants who were treated with oral paracetamol had higher rates of NEC and mortality in comparison to other treatment options. Infants treated before postnatal day 7 had higher rates of mortality and BPD/death than infants who were conservatively managed or treated beyond day 7 ( $p=0.009$ and 0.007 , respectively). In preterm infants born at $<29$ weeks of gestation with moderate-to-large PDA, medical treatment did not show any reduction in the rates of open PDA at discharge, surgical or prematurity-related secondary outcomes. In addition to the high incidence of spontaneous closure of PDA in the first week of life, early treatment ( $<7$ days) was associated with higher rates of mortality and BPD/death.

Keywords: patent ductus arteriosus, preterm, conservative, management, morbidity, mortality, ibuprofen, paracetamol

\section{INTRODUCTION}

Patent ductus arteriosus (PDA) is the most common cardiovascular condition in preterm infants. Although the ductus arteriosus (DA) is closed spontaneously in most of the infants born at $>28$ weeks of gestation (i.e., at the end of the first week of life), persistent patency of the DA is observed in $50-70 \%$ of infants born at $<28$ weeks of gestation, and lasts for weeks after birth $(1,2)$.

PDA is associated with mortality and morbidities including necrotizing enterocolitis (NEC), pulmonary hemorrhage, intraventricular hemorrhage (IVH), retinopathy of prematurity (ROP), bronchopulmonary dysplasia (BPD), and poor neurodevelopmental outcomes. These morbidities are caused by the left-to-right shunt through the DA that may result in pulmonary hyperperfusion and systemic hypoperfusion (3-6). This association has encouraged neonatologists to treat PDA in order to reduce these associated morbidities, but there remains a wide variety of management options for PDA across centers worldwide $(7,8)$.

Despite PDA's association with prematurity-related morbidities, no randomized controlled trial to date has demonstrated improvements in BPD, long-term neurodevelopmental outcomes or mortality after medical or surgical treatment of PDA (1, 4, 9-11). Therefore, centers have been performing conservative follow-ups for PDA, especially since higher rates of spontaneous closure rates have been reported in the current era $(12,13)$. A recent study that compared early routine treatment (ERT) of PDA with conservative management showed that ERT did not reduce either PDA ligations or the presence of a PDA at discharge, and did not improve secondary outcomes, However, ERT was associated with higher rates of late-onset sepsis (LOS) and death in infants born at $>26$ weeks of gestation (14). Therefore, we aimed to establish a prospective online registry database to examine the variations in PDA management for a nationallybased cohort, and evaluate the effects of PDA management strategies on the rates of PDA closure, PDA ligation, associated morbidities, and survival in preterm infants.

\section{MATERIALS AND METHODS}

After the establishment of the Experiences in Timing and Choices for Ductal Closure in Patent Ductus Arteriosus (INTERPDA) Study Online Registry in January 2017, a multicenter prospective observational nationally-based cohort study was conducted. Infants who were born at gestational weeks between $24^{0 / 7}$ and $28^{6 / 7}$ and underwent echocardiography in first 3 weeks of life after birth were included. Clinical directors in neonatal intensive care units (NICUs) nationwide were made aware of the study, and 24 NICUs participated. The NICUs were asked to add all hospitalized patients per day to the registry database using an online standard, patientspecific electronic case report form (eCRF) for a 2-years period. Data were then collected prospectively and registered by trained neonatologists.

The study was approved by the Online Studies Scientific Steering Committee of the Turkish Neonatal Society and by the Institutional Review Board of Ankara University. Written informed consent was obtained from the parents or guardians of the newborns. The study was registered at ClinicalTrials.gov (NCT02910609).

The eCRF included demographic and clinical findings including gestational age, birth weight, gender, type of delivery, the presence of prolonged premature rupture of 


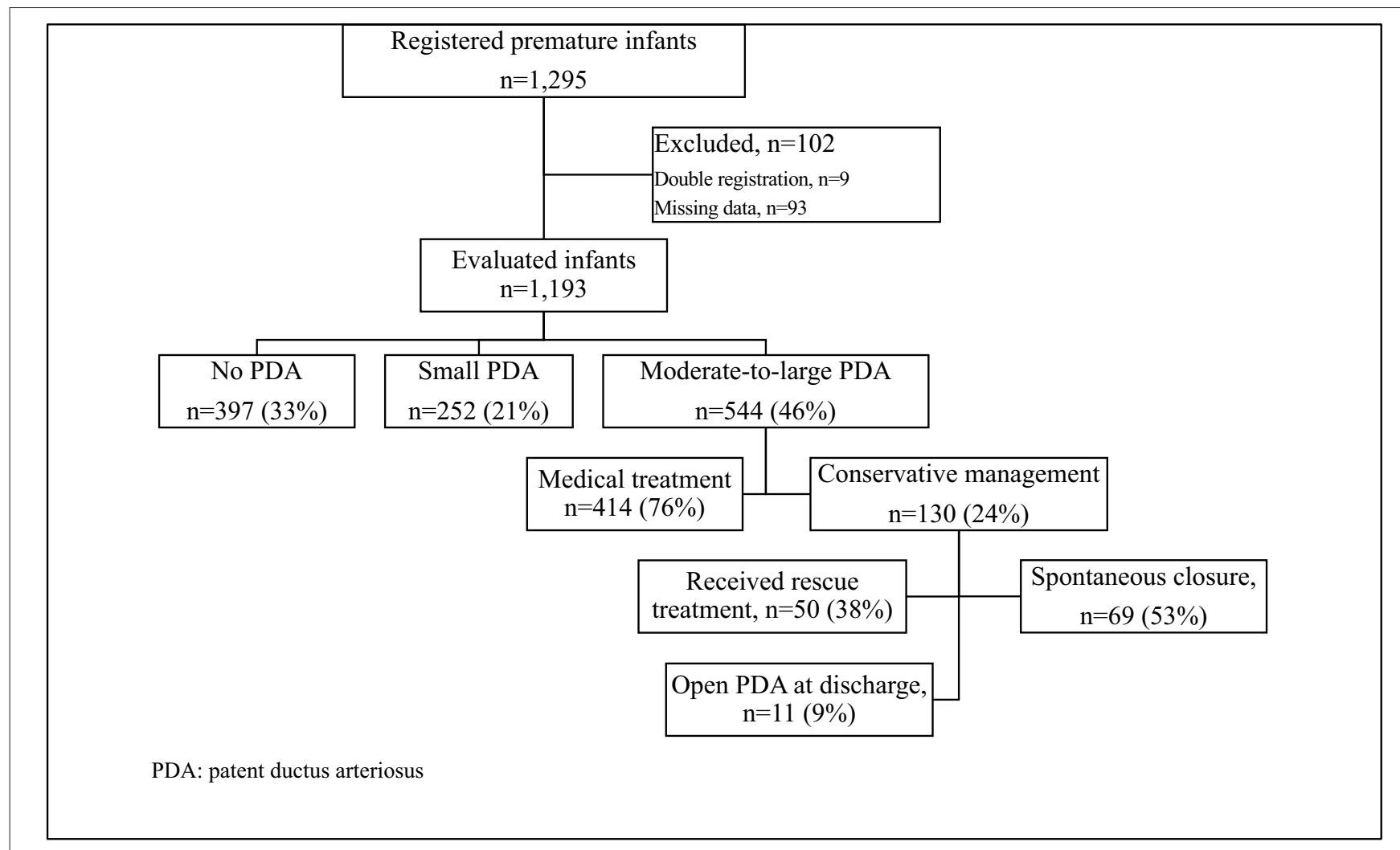

FIGURE 1 | The flow chart of the study.

membranes (PPROM) which was defined as rupture of membranes $>18 \mathrm{~h}$ before labor and before 37 weeks' gestation, antepartum preeclampsia (15); clinical chorioamnionitis, the use of any antenatal steroid, respiratory distress syndrome (RDS) (16), clinical or culture proven early-onset sepsis in addition to echocardiographic assessment results, type of PDA, management provided to the infants (conservative or medical), the timing of any medication used, type of preferred drug, outcomes of management on ductal closure at discharge, surgical ligation, and adverse events. Associated morbidities such as culture proven LOS, NEC (17), IVH (18), ROP (19), BPD (20), and mortality were also recorded.

\section{Echocardiographic Assessment}

Diagnosis of PDA was based on clinical and/or echocardiographic studies, which included 2-dimensional imaging, M-mode, color flow mapping, and Doppler interrogation. A moderate-to-large PDA was defined as an internal ductus diameter $>1.5 \mathrm{~mm}$, left atrium-to-aortic root ratio $>1.5$, and reverse diastolic flow in the descending aorta. A ductus that failed to meet these criteria was defined as small PDA.

\section{Management of PDA}

The decision for the management of PDA was left up to each center according to their standard practices.
TABLE 1 | The demographic data of the infants included in INTERPDA study.

No. of patients $(n=1,193)$

\begin{tabular}{lc}
\hline Gestational age (wk) & $26.7 \pm 1.4$ \\
Birth weight (g) & $926 \pm 243$ \\
Gender (male), $n$ (\%) & $605(51)$ \\
Type of delivery (C/S), $n$ (\%) & $949(79)$ \\
Multiple gestation, $n$ (\%) & $231(19)$ \\
PPROM, $n$ (\%) & $288(24)$ \\
Preeclampsia, $n(\%)$ & $305(26)$ \\
Chorioamnionitis, $n(\%)$ & $112(9)$ \\
Antenatal steroid, $n(\%)$ & $83(70)$ \\
Delivery room intubation, $n$ (\%) & $555(46)$ \\
Surfactant use, $n(\%)$ & $956(80)$ \\
RDS, $n$ (\%) & $986(83)$ \\
Early-onset sepsis, $n$ (\%) & $436(36)$
\end{tabular}

$C / S$, cesarean section; PPROM, prolonged premature rupture of membranes; RDS, respiratory distress syndrome.

${ }^{\star}$ Data given mean $\pm S D$.

Infants with moderate-to-large PDA were grouped according to their PDA management as conservative approach or medical treatment. Patients' demographic and clinical findings, outcomes of preferred PDA management, rates of associated morbidities, 
TABLE 2 | Demographic and clinical findings of the conservatively managed and medically treated groups of the infants with moderate-to-large PDA.

\begin{tabular}{|c|c|c|c|}
\hline & $\begin{array}{c}\text { Conservative } \\
(n=130)\end{array}$ & $\begin{array}{l}\text { Medical } \\
(n=414)\end{array}$ & $\boldsymbol{P}$ \\
\hline Gestational age $(w)^{\star}$ & $26.5 \pm 1.4$ & $26.5 \pm 1.5$ & 0.89 \\
\hline Birth weight $(\mathrm{g})^{\star}$ & $924 \pm 232$ & $877 \pm 230$ & 0.06 \\
\hline Gender (male), $n$ (\%) & $65(30)$ & $202(49)$ & 0.81 \\
\hline Type of delivery (C/S), $n$ (\%) & $96(74)$ & $311(75)$ & 0.77 \\
\hline Multiple gestation, $n$ (\%) & $22(17)$ & $90(22)$ & 0.23 \\
\hline PPROM, $n(\%)$ & $40(31)$ & $94(23)$ & 0.06 \\
\hline Preeclampsia, $n$ (\%) & $32(25)$ & $101(24)$ & 0.96 \\
\hline Chorioamnionitis, $n$ (\%) & $14(11)$ & $52(13)$ & 0.58 \\
\hline Antenatal steroid, $n(\%)$ & $88(68)$ & $288(70)$ & 0.68 \\
\hline Delivery room intubation, $n$ (\%) & $64(49)$ & $239(58)$ & 0.08 \\
\hline Surfactant use, $n(\%)$ & $104(80)$ & $380(92)$ & $<0.001$ \\
\hline RDS, $n(\%)$ & $108(83)$ & 392 (95) & $<0.001$ \\
\hline Early-onset sepsis, $n$ (\%) & $48(37)$ & $166(40)$ & 0.52 \\
\hline Received respiratory support, $n(\%)$ & $113(87)$ & $408(99)$ & $<0.001$ \\
\hline Duration of respiratory support $(d)^{\star \star}$ & $18(1-245)$ & $22(1-181)$ & 0.001 \\
\hline Discharged with open PDA, $n$ (\%) & $25(19)$ & $80(19)$ & 0.98 \\
\hline PDA ligation, $n(\%)$ & $8(6)$ & $29(7)$ & 0.73 \\
\hline LOS, $n(\%)$ & $71(55)$ & $216(52)$ & 0.62 \\
\hline IVH ( $\geq$ Grade 3), $n$ (\%) & $5(4)$ & $15(4)$ & $>0.05$ \\
\hline NEC, $n(\%)$ & $28(21)$ & $107(26)$ & 0.32 \\
\hline Moderate-severe BPD ${ }^{¥}, n(\%)$ & $25(47)$ & $93(49)$ & 0.84 \\
\hline Treated ROP ${ }^{\ddagger}, n(\%)$ & $14(13)$ & $63(21)$ & 0.06 \\
\hline Mortality, $n(\%)$ & $29(22)$ & $144(35)$ & 0.008 \\
\hline BPD/death, $n(\%)$ & $51(39)$ & $226(55)$ & 0.002 \\
\hline Duration of hospitalization $(\mathrm{d})^{\star \star}$ & 59 (2-253) & $62(2-357)$ & 0.79 \\
\hline
\end{tabular}

$B P D$, bronchopulmonary dysplasia; $C / S$, cesarean section; $I V H$, intraventricular hemorrhage; LOS, late-onset sepsis; NEC, necrotizing enterocolitis; PDA, patent ductus arteriosus; PPROM, prolonged premature rupture of membranes; RDS, respiratory distress syndrome; $R O P$, retinopathy of prematurity.

FInfants had at least one eye examination for ROP

$¥$ Infants survived at PMA 36 weeks' gestation.

${ }^{\star}$ Data given mean $\pm S D$, **Data given as median (range).

mortality rate, and BPD or death (BPD/death) were compared between the two groups.

\section{Statistical Analysis}

Frequency and percentage ( $n, \%)$ were used to describe categorical data. Pearson Chi-squared test was used to assess the relationship between categorical variables when the test requirements were met. Otherwise, Fisher's exact test or FisherFreeman-Halton Exact test was used to test independence between categorical variables depending on the table size. For numerical dependent variables Mann-Whitney $U$-test was used for comparisons between groups due to the fact that the parametric test assumptions were not met. Normality of numerical variables was assessed by Kolmogorov-Smirnov test. Homogeneity of group variances were evaluated by Levene test. Descriptive statistics were reported as minimum value, maximum value, median (interquartile range-IQR). In addition, mean \pm standard deviation was also given. After conducting univariate analysis to estimate effects of managements for PDA on mortality and BPD/death by using generalized estimating equations (GEE); multivariate models were evaluated with QICC criteria. All regression analysis was based on GEE, we used non-robust standard errors and accounted for the clustering of infants within center (21). Odds ratio are presented with 95\% Cl. Statistical analysis was performed using the IBMM SPSS Statistics version 23 for Windows.

\section{RESULTS}

\section{Demographic Data of the Study Group}

The final study sample included 1,193 infants after exclusion of 102 from a total of 1,295 because of double-record or missing data (Figure 1). The mean gestational age and birth weight of infants were $26.7 \pm 1.4$ weeks and $926 \pm 243$ g, respectively. Of the 1,193, 523 (44\%) infants were born at $<27$ weeks' gestation, and $730(62 \%)$ weighed $<1,000 \mathrm{~g}$. The prenatal and neonatal demographic characteristics of the infants enrolled in the study are displayed in Table $\mathbf{1}$.

The median of the echocardiographic assessment time was 3 days (interquartile range, $\mathrm{IQR}=2$ days). The incidence of small PDA and no PDA was 252 (21\%) and 397 (33\%), respectively; whereas $544(46 \%)$ patients had moderate-to-large PDA on echocardiographic evaluation. The incidence of moderate-tolarge PDA was $63,60,45,40$, and $38 \%$ according to a gestational age of $24,25,26,27$, and 28 weeks, respectively.

\section{Data of Infants With Moderate-to-Large PDA}

One hundred thirty (24\%) infants with moderate-to-large PDA were managed conservatively, in contrast to 414 (76\%) infants who received medical treatment. The data for these infants are displayed in Table 2. Infants with moderate-to-large PDA in both the conservative and medically-treated groups showed similar gestational age, birth weight, incidences of maternal preeclampsia, chorioamnionitis and PPROM, antenatal steroid use, and early onset sepsis $(p>0.05)$. Higher incidences of delivery room intubation, RDS, and surfactant use were present in medically treated infants $(p<0.05)$.

The respiratory support of infants according to gestational age and PDA management is shown in Figure 2. More infants received any respiratory support in medical treatment group than infants in conservative group (99 vs. 87\%, $p<0.001$ ). The rate of non-invasive ventilation use as respiratory support was higher in conservatively-managed infants with moderateto-large PDA $(p=0.004)$, whereas the number of infants receiving mechanical ventilation was higher among medicallytreated patients $(p=0.011)$.

There were no differences in the rates of open PDA at discharge, surgical ligation, LOS, NEC (any stage), ROP (received treatment who had at least one eye examination for ROP), IVH ( $\geq$ Grade 3), BPD [moderate-to-severe who survived at postmenstrual [PMA] 36 weeks of gestation] between the groups $(p>0.05)$, but infants who were medically treated had higher rates of mortality (OR 1.82, 95\% Cl 1.15-2.89, $p=0.011$ ), and BPD/death (OR 1.81 

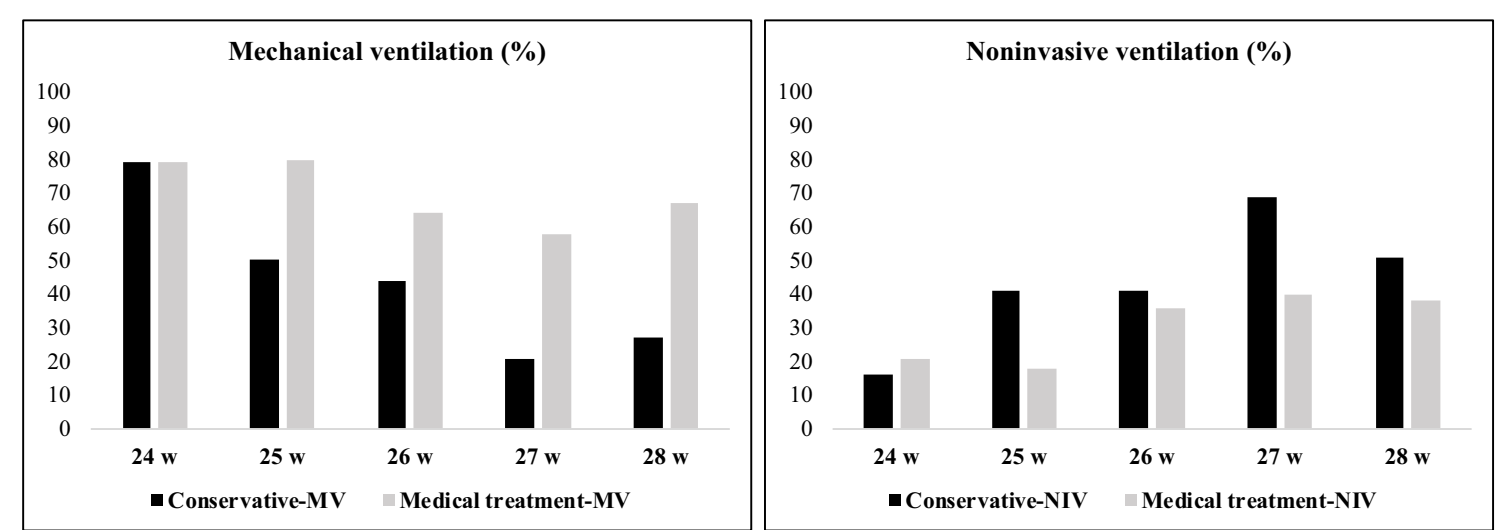

MV: mechanical ventilation; NIV: noninvasive ventilation

FIGURE 2 | The respiratory support of infants and PDA management.

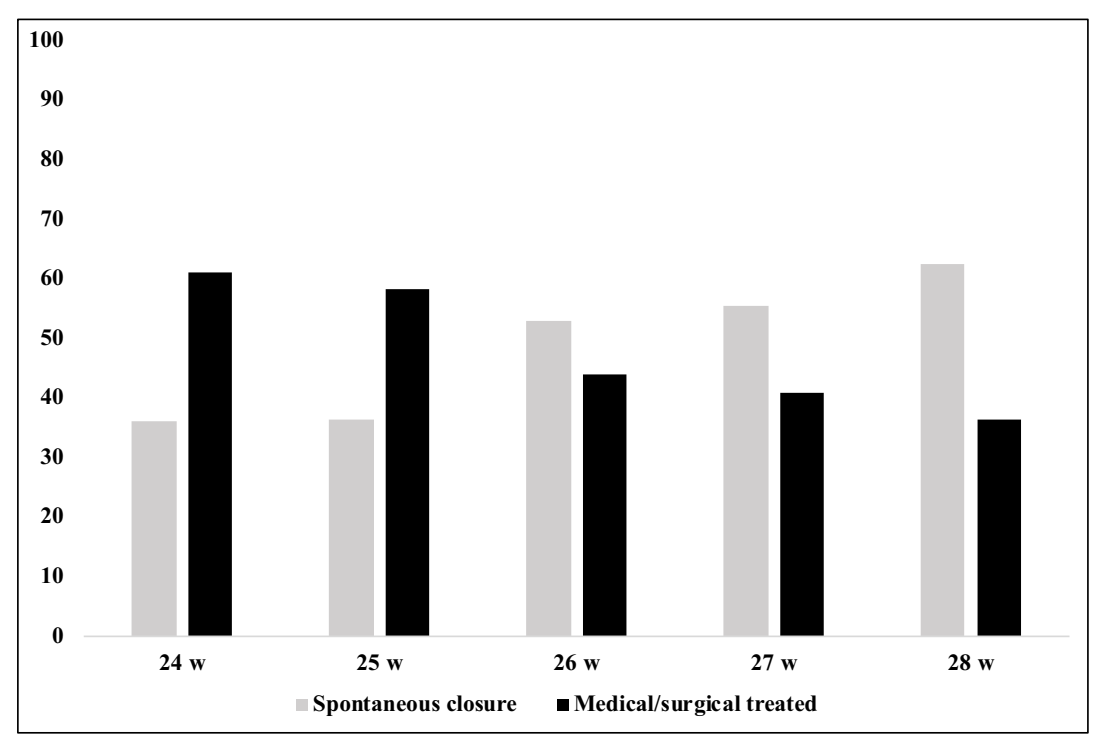

FIGURE 3 | The rates of spontaneous closure or medically/surgical treated ductus according to gestational age.

95\% Cl 1.20-2.71, $p=0.004$ ) (Table 2). However, multivariate analysis including perinatal factors (gestational age, birth weight, chorioamnionitis, delivery room intubation) showed that medical treatment was associated with increased risk for mortality (OR 1.68, 95\% Cl 1.01-2.80, $p=0.046$ ), but decreased risk for $\mathrm{BPD} /$ death (OR $0.59,95 \% \mathrm{Cl} 0.37-0.92$, $p=0.022$ ).

Eighty (62\%) of the 130 infants who were managed conservatively did not receive any rescue treatment during their hospitalization. PDA closure before hospital discharge was observed in 69 infants. The spontaneous closure rate increased with gestational age and reached a peak level of $63 \%$ in infants born at 28 weeks of gestation (Figure 3 ).

We performed a secondary analysis according to gestational age ( $<27$ weeks and $\geq 27$ weeks) to evaluate the effects of PDA management on any of the outcomes (Table 3 ).
Despite similar incidences of open PDA at discharge, PDA ligation, and mortality between groups, higher rates of NEC and $\mathrm{BPD} /$ death were observed in medically treated infants born at $\geq 27$ weeks of gestation ( $p=0.026$ and $p=0.025$, respectively). These infants had higher incidences of RDS and surfactant use, and longer duration of respiratory support (median 24 days vs. 12 days, $p<0.001$ ) compared to conservatively managed infants. Univariate analysis showed that medical treatment was associated with an increased the risk of NEC and BPD/death (OR 2.7, 95\% $\mathrm{Cl} 1.09-6.68, p=0.031$, and OR 2.12, 95\% Cl 1.07-4.20, $p=0.03$, respectively) in infants born at $\geq 27$ weeks of gestation, however multivariate analysis could not demonstrate the similar effect for BPD/death.

The groups did not differ in duration of respiratory support and rate of mechanical ventilation in infants born at $<27$ weeks of gestation. The rates of open PDA at discharge, 
TABLE 3 | Outcomes of infants born $<27$ weeks and $\geq 27$ weeks' gestation.

\begin{tabular}{|c|c|c|c|c|c|c|}
\hline & \multicolumn{3}{|c|}{$<27$ weeks $(n=282)$} & \multicolumn{3}{|c|}{$\geq 27$ weeks $(n=262)$} \\
\hline & $\begin{array}{l}\text { Conservative } \\
\qquad(n=68)\end{array}$ & $\begin{array}{l}\text { Medical } \\
(n=214)\end{array}$ & $P$ & $\begin{array}{c}\text { Conservative } \\
\qquad(n=62)\end{array}$ & $\begin{array}{l}\text { Medical } \\
(n=200)\end{array}$ & $P$ \\
\hline \multicolumn{7}{|c|}{ DEMOGRAPHIC AND CLINICAL DATA } \\
\hline Gestational age $\left(\right.$ week) ${ }^{*}$ & $25.3 \pm 0.9$ & $25.3 \pm 0.8$ & 0.37 & $27.7 \pm 0.5$ & $27.8 \pm 0.5$ & 0.29 \\
\hline Birth weight $(g)^{\star}$ & $796 \pm 158$ & $754 \pm 170$ & 0.06 & $1,066 \pm 219$ & $1,009 \pm 212$ & 0.07 \\
\hline Gender (male), $n$ (\%) & $31(46)$ & $107(50)$ & 0.52 & $34(55)$ & $95(47)$ & 0.31 \\
\hline Type of delivery (C/S), $n$ (\%) & $47(69)$ & $146(68)$ & 0.89 & $49(79)$ & $165(82)$ & 0.53 \\
\hline Multiple gestation, n (\%) & $12(18)$ & $42(20)$ & 0.71 & $10(16)$ & $48(24)$ & 0.19 \\
\hline PPROM, $n(\%)$ & $22(32)$ & $67(31)$ & 0.87 & $18(29)$ & $27(13)$ & 0.005 \\
\hline Preeclampsia, $n$ (\%) & $16(23)$ & $46(21)$ & 0.72 & $16(26)$ & $55(27)$ & 0.79 \\
\hline Chorioamnionitis, $n(\%)$ & $11(16)$ & $36(17)$ & 0.90 & $3(5)$ & $16(8)$ & 0.4 \\
\hline Antenatal steroid, $n(\%)$ & $45(66)$ & $132(62)$ & 0.50 & $43(69)$ & $156(78)$ & 0.16 \\
\hline Delivery room intubation, $n$ (\%) & $40(59)$ & $154(72)$ & 0.04 & $24(39)$ & $85(42)$ & 0.59 \\
\hline Surfactant use, $n(\%)$ & $61(90)$ & $206(96)$ & 0.09 & $44(71)$ & $177(88)$ & 0.001 \\
\hline RDS, $n(\%)$ & $60(88)$ & $203(95)$ & 0.05 & $47(76)$ & $186(93)$ & $<0.001$ \\
\hline Early-onset sepsis, $n$ (\%) & $27(40)$ & $94(44)$ & 0.54 & $21(34)$ & $72(36)$ & 0.76 \\
\hline Received respiratory support, $n(\%)$ & $61(90)$ & $213(99)$ & $<0.001$ & $52(84)$ & $195(97)$ & $<0.001$ \\
\hline Duration of respiratory support (d) ${ }^{\star \star}$ & $26(2-245)$ & $23(1-150)$ & 0.91 & $14(1-96)$ & $22(2-181)$ & 0.001 \\
\hline \multicolumn{7}{|l|}{ OUTCOMES } \\
\hline Discharged with open PDA, $n$ (\%) & $16(23)$ & $53(25)$ & 0.83 & $9(14)$ & $27(13)$ & 0.83 \\
\hline PDA ligation, $n(\%)$ & $6(9)$ & $17(8)$ & 0.81 & $2(3)$ & $12(6)$ & 0.53 \\
\hline LOS, $n(\%)$ & $44(65)$ & $24(55)$ & 0.16 & $27(43)$ & $98(49)$ & 0.45 \\
\hline IVH ( $\geq$ Grade 3), $n$ (\%) & $4(6)$ & $9(4)$ & 0.52 & $1(2)$ & $6(3)$ & $>0.05$ \\
\hline NEC, $n(\%)$ & $22(32)$ & $62(29)$ & 0.59 & $6(10)$ & $45(22)$ & 0.026 \\
\hline Moderate-severe BPD ${ }^{¥}, n(\%)$ & $18(50)$ & $57(56)$ & 0.50 & $11(50)$ & $49(47)$ & 0.80 \\
\hline Treated ROP ${ }^{\ddagger}, n(\%)$ & $11(16)$ & $45(21)$ & 0.38 & $3(5)$ & $18(9)$ & 0.42 \\
\hline Mortality, $n(\%)$ & $24(35)$ & $111(52)$ & 0.017 & $5(8)$ & $33(16)$ & 0.09 \\
\hline BPD/death, $n(\%)$ & $37(54)$ & $150(70)$ & 0.017 & $14(23)$ & $76(38)$ & 0.025 \\
\hline Duration of hospitalization (d) ${ }^{\star \star}$ & $71(2-253)$ & $54.5(2-357)$ & 0.34 & $54(2-120)$ & $63(3-180)$ & 0.018 \\
\hline
\end{tabular}

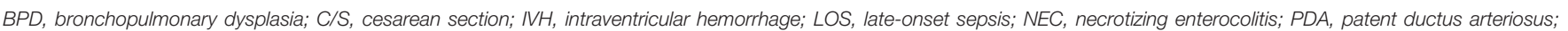
$P P R O M$, prolonged premature rupture of membranes; RDS, respiratory distress syndrome; $R O P$, retinopathy of prematurity.

¥Infants had at least one eye examination for ROP.

$¥$ Infants survived at PMA 36 weeks' gestation.

${ }^{\star}$ Data given mean $\pm S D$, ${ }^{\star *}$ Data given as median (range).

surgical ligation, and morbidities did not differ significantly in those who were medically treated and those conservatively managed, but medically treated infants had higher rates of mortality and $\mathrm{BPD} /$ death. Univariate analysis indicated odds of increased rates of mortality and $\mathrm{BPD} /$ death associated with medical treatment in infants born at $<27$ weeks of gestation (OR 1.97, 95\% Cl 1.12-3.47, $p=0.19$, and OR $1.96,95 \% \mathrm{Cl}$ $1.12-3.44, p=0.19$ ), however these were not significant on multivariate analysis.

\section{Data Related to Timing and Preferred Medical Treatment Options}

The preferred treatment options were ibuprofen (intravenous $36 \%$, oral $31 \%$ ), and paracetamol (intravenous $26 \%$, oral $7 \%$ ) as the initial course; indomethacin was not used in any patient. The median starting time of first-course pharmacological treatment was 3 days ( $\mathrm{IQR}=2.25$ days). The timing of medical treatment was not found to be associated with mortality or morbidities. The most common side effects of drug treatment were impairment of renal function and risk of bleeding, which were mostly reported with ibuprofen treatment.

The incidences of open PDA at discharge, surgical ligation, LOS, BPD, and ROP were similar according to the firstcourse medication selection. However, infants treated with oral paracetamol had higher rates of NEC and mortality, and infants treated with intravenous paracetamol had a higher rate of BPD/death (Table 4).

Ninety-six (26\%) of the 362 infants received a second course of treatment with ibuprofen (intravenous 34\%, oral 35\%) and paracetamol (intravenous 23\%, oral 8\%), and 29 infants received a third course of treatment mostly with intravenous paracetamol (59\%).

Infants who received treatment before postnatal day 7 had higher rates of mortality and $\mathrm{BPD} /$ death than infants who were 
TABLE 4 | Morbidities and mortality according to treatment options.

\begin{tabular}{|c|c|c|c|c|c|}
\hline & $\begin{array}{l}\text { IV ibuprofen } \\
(n=148)\end{array}$ & $\begin{array}{l}\text { Oral ibuprofen } \\
\qquad(n=129)\end{array}$ & $\begin{array}{l}\text { IV paracetamol } \\
(n=108)\end{array}$ & $\begin{array}{l}\text { Oral paracetamol } \\
\qquad(n=29)\end{array}$ & $p$ \\
\hline Discharged with open PDA, $n(\%)$ & $28(19)$ & $19(15)$ & $24(22)$ & $9(31)$ & 0.18 \\
\hline Surgical ligation, $n$ (\%) & $11(7)$ & $10(8)$ & $6(6)$ & $2(7)$ & 0.91 \\
\hline LOS, $n(\%)$ & $82(64)$ & $65(51)$ & $54(61)$ & $10(53)$ & 0.08 \\
\hline $\mathrm{IVH}(\geq \mathrm{Gr} 3), n(\%)$ & $3(2)$ & $6(5)$ & $5(5)$ & $1(3)$ & 0.61 \\
\hline NEC, $n(\%)$ & $40(27)$ & $32(25)$ & $20(18)$ & $15(52)$ & 0.004 \\
\hline Treated ROP $\mathrm{RO}^{\ddagger}, n(\%)$ & $22(15)$ & $18(14)$ & $18(17)$ & $5(17)$ & 0.93 \\
\hline Moderate-severeBPD ${ }^{¥}, n$ (\%) & $36(44)$ & $39(59)$ & $28(58)$ & $3(30)$ & 0.11 \\
\hline Mortality, $n(\%)$ & $46(31)$ & $34(26)$ & $48(44)$ & $16(55)$ & 0.002 \\
\hline BPD/death, $n$ (\%) & $75(51)$ & $63(49)$ & $71(66)$ & $17(59)$ & 0.04 \\
\hline
\end{tabular}

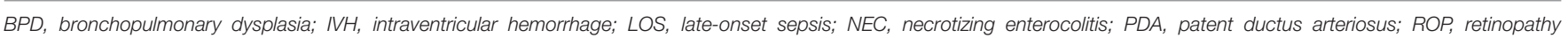
of prematurity.

FInfants had at least one eye examination for ROP.

$¥$ Infants survived at PMA 36 weeks' gestation.

TABLE 5 | Data of mortality, surgical ligation and morbidities in infants who were conservatively managed or medically treated infants ( $<7$ days and $\geq 7$ days).

\begin{tabular}{|c|c|c|c|c|}
\hline & \multirow[t]{2}{*}{$\begin{array}{c}\text { Conservative } \\
(n=130)\end{array}$} & \multicolumn{2}{|c|}{$\begin{array}{l}\text { Medical treatment } \\
\quad(n=414)\end{array}$} & \multirow[t]{2}{*}{$p$} \\
\hline & & $\begin{array}{l}<7 \text { days } \\
(N=363)\end{array}$ & $\begin{array}{l}\geq 7 \text { days } \\
(N=51)\end{array}$ & \\
\hline Discharged with open PDA, $n$ (\%) & $25(19)$ & $72(20)$ & $8(16)$ & 0.78 \\
\hline PDA ligation, $n$ (\%) & $8(6)$ & $24(7)$ & $5(10)$ & 0.66 \\
\hline LOS, $n$ (\%) & $71(55)$ & $188(52)$ & $28(55)$ & 0.81 \\
\hline $\mathrm{IVH}(\geq \mathrm{Gr} 3), n(\%)$ & $5(3.8)$ & $13(3.6)$ & $2(3.9)$ & 0.32 \\
\hline NEC, $n(\%)$ & $28(21)$ & $91(25)$ & $16(31)$ & 0.38 \\
\hline Moderate-severe BPD ${ }^{¥}, n(\%)$ & $25(47)$ & $80(48)$ & $13(54)$ & 0.83 \\
\hline Treated ROP $\ddagger$, n (\%) & $14(13)$ & $56(22)$ & $7(16)$ & 0.12 \\
\hline Mortality, $n(\%)$ & $29(22)$ & $131(36)$ & $13(25)$ & 0.009 \\
\hline BPD/death, $n$ (\%) & $51(39)$ & $201(55)$ & $25(49)$ & 0.007 \\
\hline
\end{tabular}

$B P D$, bronchopulmonary dysplasia; $N H$, intraventricular hemorrhage; LOS, late-onset sepsis; NEC, necrotizing enterocolitis; PDA, patent ductus arteriosus; ROP, retinopathy of prematurity.

FInfants had at least one eye examination for ROP.

¥ Infants survived at PMA 36 weeks' gestation.

conservatively-managed or treated after day $7(p=0.009$ and $p=$ 0.007, respectively) (Table 5).

\section{DISCUSSION}

In this first nationwide study on the management of PDA in preterm infants born at $<29$ weeks of gestation, we found that there are management variations between NICUs across Turkey. Although most of the patients with moderate-to-large PDA received medical treatment, there was an increasing trend toward the conservative approach. Medical treatment had no effect on the incidence of surgical ligation or prematurity-related morbidities in the overall study group, and early treatment before day 7 of life was associated with higher mortality and BPD/death.
Medical treatment was additionally associated with higher rates of NEC in infants who were born at $>27$ weeks of gestation.

PDA is present in up to $70 \%$ of preterm infants born at $<28$ weeks of gestation $(2,5)$. The proportion of very low birth weight (VLBW) infants with PDA was reported to be $36 \%$ and $38 \%$ in Japan and Canadian networks, respectively (22). According to the Korean Neonatal Network 2017 annual report, 45\% of VLBW infants had a PDA (23). In the present study, moderate-to-large PDA was present in $46 \%$ of preterm infants born at $<29$ weeks of gestation and increased to $63 \%$ in patients born at 24 weeks of gestation.

Management of PDA in extremely preterm infants remains a topic of debate. Treatment to induce ductal closure has been widely practiced until the last decade, despite lack of evidence that it decreases morbidities and mortality. Meta-analyses of trials using non-steroidal anti-inflammatory drugs have shown effectiveness in accelerating ductal closure, but no reduction in neonatal morbidities regardless of the drugs used, indication, timing, gestational age, or route of administration (1). While medical treatment and surgical ligation can close the ductus, such treatment has had side effects $(11,24)$. The trend toward conservative treatment has been fueled by recent experience with conservative approaches that demonstrated improved neonatal outcomes and a high rate of spontaneous ductal closure at discharge. Lokku et al. demonstrated that an increasing rate of conservative management of PDA occurred alongside a decrease in medical and/or surgical treatment between 2006 and 2012 in Canada (25). An American cohort study with a large population from 280 NICUs showed a significant decrease in diagnosis and medical/surgical treatment of PDA with no evidence of increased morbidities (26). The recent PDA-TOLERATE trial is the only randomized trial that compared routine treatment of a moderate-to-large PDA present at the end of the first week of life in infants born at $<28$ weeks of gestation to a conservative approach in reducing neonatal morbidities and/or death. It showed that routine treatment of PDA decreased the incidence of PDA at discharge, but failed to decrease the incidence of $\mathrm{BPD}, \mathrm{BPD} /$ death, and morbidities. Routine treatment of PDA 
also appeared to increase the incidence of LOS and death among infants born at $>26$ weeks of gestation (14). Similarly, the present study's results showed a trend toward the conservative approach in our NICUs across Turkey. In this study, although medical treatment of PDA did not show any reduction in the rates of open PDA at discharge, surgical ligation or neonatal morbidities; it was associated with increased mortality among infants born at $<29$ weeks of gestation. Medical treatment was preferred in more severe cases in which more mature preterm infants were receiving respiratory support by clinicians. However, subgroup analysis in infants born at $<27$ weeks of gestation showed that conservative management was not inferior to medical treatment in patients with similar characteristics.

The role played by prolonged PDA exposure in the development of morbidities remains unclear. Studies that compared infants who received indomethacin within the first 3 days of life to infants who received indomethacin only if PDA persisted beyond 7 days with specific rescue criteria showed that infants who received early treatment required less ventilatory and inotropic support and experienced a lower rate of BPD and BPD/death (27-29). Jensen et al. reported that prophylactic-used indomethacin reduced the rates of BPD and BPD/death (30). These studies enrolled and treated infants whose PDA may have been spontaneously closed at the end of the first week. A recent PDA-TOLERATE trial showed that no effect was had on the incidence of BPD if either routine treatment of moderate-to-large PDA was given after the first week or if no treatment was given until severe respiratory or hemodynamic symptoms developed (14). Clyman et al. showed that a significant increase in the incidence of $\mathrm{BPD} /$ death required at least 7-13 days of untreated moderate-to-large PDA in infants born at $<28$ weeks; additional exposure did not add an increase to the incidence of BPD/death (31). In the present cohort study of infants born before 29 weeks of gestation, it was found that early treatment before 7 days of life was associated with higher mortality and BPD/death. Treatment at or after 7 days was not associated with an increase in the risk of incidences of any morbidities. Long-term recent studies demonstrated that a conservative approach, even in the case of prolonged PDA, did not increase the risk of neurodevelopmental impairment $(13,32)$.

The pharmacological agents used to close the DA are prostaglandin synthase inhibitors such as indomethacin and ibuprofen, or a cyclooxygenase inhibitor like acetaminophen (1, 33-35). Meta-analyses on the efficacy of ibuprofen and indomethacin showed no difference in effectiveness; although ibuprofen can have less intestinal and renal side effects (11). Another meta-analysis that evaluated the association between placebo, indomethacin, ibuprofen, and acetaminophen on PDA closure suggested that a high dose of oral ibuprofen was associated with a higher incidence of PDA closure (36). In some randomized controlled trials, oral paracetamol was found to be as effective and safe as ibuprofen in PDA treatment (37-39). According to the Cochrane review, paracetamol was as effective as ibuprofen without showing any difference in neurodevelopmental outcomes (24). Ibuprofen was the most preferred agent followed by paracetamol (67 vs. $33 \%$ ) in the present study. The choice of medical agent did not affect the incidence of LOS, BPD, ROP, IVH, surgical ligation, or death. But, unlike the other options, paracetamol was associated with higher rates of NEC, mortality and $\mathrm{BPD} /$ death which were not reported in previous studies $(38,39)$.

The present study had a few limitations. First, it was an observational study. However, to the authors' knowledge, the present report represents one of the largest multicenter studies on the outcomes of persistent PDA. Availability of data from a large national prospective cohort of preterm infants who were admitted to tertiary NICUs strengthened these results. Second, this report details the variations and trends in PDA management between NICUs. The design of the study was such that each center used their individual preferences in the decision of PDA management or treatment selection. Potential of unmeasured markers of early severity of illness and the potential for improper adjustment for each subject's observed time in the study which might be attributable to survivor treatment selection could cause bias, and this should be kept in mind when discussing the effect of treatment on the mortality. Although variable practices of PDA management among centers might have affected the natural course of PDA, this afforded the study the chance to compare the different approaches, agents used, timing of treatment, and PDA outcomes. The authors believe that the results of this large clinical database will lead to further studies to improve uniform guidance for the management of PDA.

\section{CONCLUSION}

This study provides a summary of the current state of practice for moderate-to-large PDAs in our country, and we think that it will be an important addition to the literature by reporting various treatment and outcome rates. While the majority of NICUs still prefer early symptomatic treatment for moderate-tolarge PDA at postnatal 3-5 days of life, there has been a trend toward implementing conservative approaches. As a descriptive study, we observed that medical treatment did not change the incidences of open PDA at discharge, surgical ligation, and morbidities, but was shown to be associated with an increase with mortality. Early medical treatment prior to 7 days of life was not associated with a reduction of the incidences of surgical ligation or morbidities and was associated with higher rates of mortality and BPD/death. Although a conservative approach seems to be preferable option for infants born at $<29$ weeks of gestation that are suffering from moderate-to-large PDA, we still need well-designed randomized controlled trials to have a final recommendation.

\section{DATA AVAILABILITY STATEMENT}

The raw data supporting the conclusions of this article will be made available by the authors, without undue reservation.

\section{ETHICS STATEMENT}

The study was approved by the Online Studies Scientific Steering Committee of the Turkish Neonatal Society and by 
the Institutional Review Board of Ankara University. Written informed consent was obtained from the parents or guardians of the newborns.

\section{AUTHOR CONTRIBUTIONS}

EO and OE contributed substantially to article conception and design and drafted the manuscript. ZA, ND, HK, IG, SE, MC, GB, FO, HS, YC, HO, NK, BA, MT, KC, DA, AB, KT, MO, FT, and $\mathrm{EE}$ participated in acquisition of data. SA critically revised it. All authors gave their final approval to this manuscript and agree to be accountable for all aspects of the work, ensuring integrity and accuracy.

\section{FUNDING}

This study was supported by Turkish Neonatal Society with grant number 1-2017, received by EO. The financial fund was used to create the Turkish INTERPDA Study Online Registry database.

\section{ACKNOWLEDGMENTS}

We thank the Turkish Neonatal Society for supporting the project, all collaborator NICUs and the following investigators,

\section{REFERENCES}

1. Sankar MN, Bhombal S, Benitz WE. PDA: to treat or not to treat. Congenital Heart Disease. (2019) 14:46-51. doi: 10.1111/chd.12708

2. Sung SI, Chang YS, Chun JY, Yoon SA, Yoo HS, Ahn SY, et al. Mandatory closure versus nonintervention for patent ductus arteriosus in very preterm infants. J Pediatr. (2016) 177:66-71.e1. doi: 10.1016/j.jpeds.2016.06.046

3. Sosenko IR, Fajardo MF, Claure N, Bancalari E. Timing of patent ductus arteriosus treatment and respiratory outcome in premature infants: a double-blind randomized controlled trial. J Pediatr. (2012) 160:929-35. e921. doi: 10.1016/j.jpeds.2011.12.031

4. Mirea L, Sankaran K, Seshia M, Ohlsson A, Allen AC, Aziz K, et al. Canadian Neonatal Network. Treatment of patent ductus arteriosus and neonatal mortality/morbidities: adjustment for treatment selection bias. J Pediatr. (2012) 161:689-94 e681. doi: 10.1016/j.jpeds.2012.05.007

5. Clyman RI. The role of patent ductus arteriosus and its treatments in the development of bronchopulmonary dysplasia. Semin Perinatol. (2013) 37:102-7. doi: 10.1053/j.semperi.2013.01.006

6. Madan JC, Kendrick D, Hagadorn JI, Frantz ID 3rd; National Institute of Child Health and Human Development Neonatal Research Network. Patent ductus arteriosus therapy: impact on neonatal and 18-month outcome. Pediatrics. (2009) 123:674-81. doi: 10.1542/peds.2007-2781

7. Jansen EJS, Dijkman KP, van Lingen RA, de Vries WB, Vijlbrief DC, de Boode WP, et al. Using benchmarking to identify inter-centre differences in persistent ductus arteriosus treatment: can we improve outcome? Cardiol Young. (2017) 27:1488-96. doi: 10.1017/S104795111700052X

8. Edstedt Bonamy AK, Gudmundsdottir A, Maier RF, Toome L, Zeitlin J, Bonet $\mathrm{M}$, et al. collaborators from the EPICE Research Group. Patent ductus arteriosus treatment in very preterm infants: a European populationbased cohort study (EPICE) on variation and outcomes. Neonatology. (2017) 111:367-75. doi: 10.1159/000454798

9. Benitz WE. Committee on fetus and newborn, american academy of pediatrics. Patent ductus arteriosus in preterm infants. Pediatrics. (2016) 137:e20153730. doi: 10.1542/peds.2015-3730 as the members of the Turkish Neonatal Society INTERPDA Study Group: Begum Atasay (Ankara University School of Medicine, Ankara, Turkey), Esin Koc (Gazi University School of Medicine, Ankara, Turkey), Derya Yalinkilic (Diyarbakir Gazi Yasargil Training and Research Hospital, Diyarbakir, Turkey), Suheyla Ozkutlu (Koru Hospital, Ankara, Turkey), Sinan Uslu (University of Health Sciences, Sisli Etfal Hamidiye Training and Research Hospital, Istanbul, Turkey), Mustafa Kara (Ataturk University School of Medicine, Erzurum, Turkey), Mustafa Kir (Dokuz Eylul University School of Medicine, Izmir, Turkey), Ozmert Ozdemir (Pamukkale University School of Medicine, Denizli, Turkey), Bilge Bayraktar, Yilmaz Yozgat (Bezmialem University School of Medicine, Istanbul, Turkey), Sibel Ozumut, Sertac Aslanoglu (Medeniyet University School of Medicine, Istanbul, Turkey), Kurthan Mert, Selvi Gulasi (Adana Numune Education and Training Hospital, Adana), Oguz Tuncer (Yuzuncu Yil University School of Medicine, Van, Turkey), Sebnem Calkavur, Senem Alkan Ozdemir (University of Health Sciences, Izmir Behcet Uz Children's Hospital, Izmir, Turkey), Tolga Celik (Hacettepe University School of Medicine, Ankara, Turkey), Mahmut Mutlu, Sebnem Kader (Karadeniz Teknik University School of Medicine, Trabzon, Turkey). We would like to thank to Dr. Hatice Yagmur Zengin (Department of Biostatistics, Hacettepe University School of Medicine, Ankara, Turkey) for her assistance with the statistical analysis.

10. Kort EJ. Patent ductus arteriosus in the preterm infant: an update on morbidity and mortality. Curr Pediatr Rev. (2016) 12:98-105. doi: 10.2174/157339631202160506001621

11. Ohlsson A, Walia R, Shah S. Ibuprofen for the treatment of patent ductus arteriosus in preterm or low birth weight (or both) infants. Cochrane Database Syst Rev. (2018) 9:CD003481. doi: 10.1002/14651858.CD0034 81.pub7

12. Letshwiti JB, Semberova J, Pichova K, Dempsey EM, Franklin OM, Miletin J. A conservative treatment of patent ductus arteriosus in very low birth weight infants. Early Hum Dev. (2017) 104:45-9. doi: 10.1016/j.earlhumdev.2016.12.008

13. Aldecoa-Bilbao V, García-Catalán MJ, Gaixa M, Clotet Caba J, Teodoro S, Figaró, et al. Neurodevelopmental impairment at two years in premature infants with prolonged patency of ductus arteriosus after a conservative approach. Am J Perinatol. (2019). doi: 10.1055/s-0039-1697674. [Epub ahead of print].

14. Clyman RI, Liebowitz M, Kaempf J, Erdeve O, Bulbul A, Håkansson S, et al. PDA-TOLERATE (PDA: TO LEave it alone or Respond And Treat Early) Trial Investigators. PDA-TOLERATE Trial: an-Explaratory randomized controlled trial of treatment of moderate-to-large patent ductus arteriosus at 1 week of age. J Pediatr. (2019) 205:41-8.e6. doi: 10.1016/j.jpeds.2018. 09.012

15. Wagner LK. Diagnosis and management of preeclampsia. Am Fam Physician. (2004) 15:2317-24. Available online at: www.aafp.org/afp

16. Ozkan H, Erdeve O, Kutman HGK. Turkish Neonatal Society guideline on the management of respiratory distress syndrome and surfactant treatment. Turk Pediatri Ars. (2018) 25:45-54. doi: 10.5152/TurkPediatriArs.2018.01806

17. Bell MJ, Ternberg JL, Feigin RD, Keating JP, Marshall R, Barton L, et al. Neonatal necrotizing enterocolitis. Therapeutic decisions based upon clinical staging. Ann Surg. (1978) 187:1-7. doi: 10.1097/00000658-197801000-00001

18. Papile LA, Burstein J, Burstein R. Incidence and evolution of subependymal and intraventricular hemorrhage: a study of infants with birth weights less than 1,500 gm. J Pediatr. (1978) 92:529-34. doi: 10.1016/s0022-3476(78)80282-0 
19. International Committee for the Classification of Retinopathy of Prematurity. The international classification of retinopathy of prematurity revisited. Arch Ophthalmol. (2005) 123:991-999. doi: 10.1001/archopht.123.7.991

20. Jobe AH, Bancalari E. Bronchopulmonary dysplasia. Am J Respir Crit Care Med. (2001) 163:1723-9. doi: 10.1164/ ajrccm.163.7.2011060

21. Kahan BC. Accounting for centre-effects in multicenter trials with a binary outcome-when, why, and how? BMC Med Res Methodol. (2014) 14:20. doi: 10.1186/1471-2288-14-20

22. Isayama T, Mirea L, Mori R, Kusuda S, Fujimura M, Lee SK, et al. On behalf of the neonatal research network of japan and the canadian neonatal network. Patent ductus arteriosus management and outcomes in Japan and Canada: comparison of proactive and selective approaches. Am J Perinatol. (2015) 32:1087-94. doi: 10.1055/s-0035-1548727

23. Korea Centers for Disease Control and Prevention. Korean Neonatal Network Annual Report 2017. Cheongju (Korea): Korea Centers for Disease Control and Prevention (2018).

24. Ohlsson A, Shah PS. Paracetamol (acetaminophen) for patent ductus arteriosus in preterm or low birth weight infants. Cochrane Database Syst Rev. (2020) 1:CD010061. doi: 10.1002/14651858.CD010061.pub4

25. Lokku A, Mirea L, Lee SK, Shah PS, on behalf of the Canadian Neonatal Network. Trends and outcomes of patent ductus arteriosus treatment in very preterm infants in Canada. Am J Perinatol. (2017) 34:44150. doi: 10.1055/s-0036-1593351

26. Bixler GM, Powers GC, Clark RH, Walker WM, Tolia VN. Changes in the diagnosis and management of patent ductus arteriosus from 2006 to 2015 in United States Neonatal Intensive Care Units. J Pediatr. (2017) 189:10512. doi: 10.1016/j.jpeds.2017.05.024

27. Liebowitz M, Clyman RI. Prophylactic indomethacin compared with delayed conservative management of the patent ductus arteriosus in extremely preterm infants: effects on neonatal outcomes. J Pediatr. (2017) 187:11926. doi: 10.1016/j.jpeds.2017.03.021

28. Kaempf JW, Wu YX, Kaempf AJ, Kaempf AM, Wang L, Grunkemeier G. What happens when the patent ductus arteriosus is treated less aggressively in very low birth weight infants? J Perinatol. (2012) 32:3448. doi: 10.1038/jp.2011.102

29. Liebowitz M, Koo J, Wickremasinghe A, Allen IE, Clyman RI. Effects of prophylactic indomethacin on vasopressor-dependent hypotension in extremely preterm infants. J Pediatr. (2017) 182:21-7 e2. doi: 10.1016/j.jpeds.2016.11.008

30. Jensen EA, Dysart KC, Gantz MG, Carper B, Higgins RD, Keszler M, et al. Association between use of prophylactic indomethacin and the risk for bronchopulmonary dysplasia in extremely preterm infants. J Pediatr. (2017) 186:34-40.e2. doi: 10.1016/j.jpeds.2017.02.003

31. Clyman RI, Hills NK, Liebowitz M, Johng S. Relationship between duration of infant exposure to a moderate-to-large patent ductus arteriosus shunt and the risk of developing bronchopulmonary dysplasia or death before 36 weeks. Am J Perinatol. (2020) 37:216-23. doi: 10.1055/s-0039-1697672
32. Kaga M, Sanjo M, Miura Y, Ono T. Safety of conservative approach for persistent patent ductus arteriosus in preterm infants: neurodevelopmental outcomes at 5 years of age. Tohoku J Exp Med. (2019) 249:15561. doi: 10.1620/tjem.249.155

33. Liebowitz M, Kaempf J, Erdeve O, Bulbul A, Håkansson S, Lindqvist J, et al. Comparative effectiveness of drugs used to constrict the patent ductus arteriosus: a secondary analysis of the PDA-TOLERATE trial (NCT01958320). J Perinatol. (2019) 39:599-607. doi: 10.1038/s41372-019-0347-4

34. Oncel MY, Erdeve O. Oral medications regarding their safety and efficacy in the management of patent ductus arteriosus. World J Clin Pediatr. (2016) 5:75-81. doi: 10.5409/wjcp.v5.i1.75

35. Oncel MY, Erdeve O. Safety of therapeutics used in management of patent ductus arteriosus in preterm infants. Curr Drug Saf. (2015) 10:10612. doi: 10.2174/1574886309999141030142847

36. Mitra S, Florez ID, Tamayo ME, Mbuagbaw L, Vanniyasingam T, Veroniki AA, et al. Association of placebo, indomethacin, ibuprofen, and acetaminophen with closure of hemodynamically significant patent ductus arteriosus in preterm infants: a systematic review and meta-analysis. JAMA. (2018) 319:1221-38. doi: 10.1001/jama.2018.1896

37. El-Farrash RA, El Shimy MS, El-Sakka AS, Ahmed MG, Abdel-Moez DG. Efficacy and safety of oral paracetamol versus oral ibuprofen for closure of patent ductus arteriosus in preterm infants: a randomized controlled trial. J Matern Fetal Neonatal Med. (2019) 32:3647-54. doi: 10.1080/14767058.2018.1470235

38. Dang D, Wang D, Zhang C, Zhou W, Zhou Q, Wu H. Comparison of oral paracetamol versus ibuprofen in premature infants with patent ductus arteriosus: a randomized controlled trial. PLoS ONE. (2013) 8:e77888. doi: 10.1371/journal.pone.0077888

39. Oncel MY, Yurttutan S, Erdeve O, Uras N, Altug N, Oguz SS, et al. Oral paracetamol versus oral ibuprofen in the management of patent ductus arteriosus in preterm infants: a randomized controlled trial. J Pediatr. (2014) 164:510-4.e1. doi: 10.1016/j.jpeds.2013. 11.008

Conflict of Interest: The authors declare that the research was conducted in the absence of any commercial or financial relationships that could be construed as a potential conflict of interest.

Copyright (C) 2020 Okulu, Erdeve, Arslan, Demirel, Kaya, Gokce, Ertugrul, Cetinkaya, Buyukkale, Ozlu, Simsek, Celik, Ozkan, Köksal, Akcan, Turkmen, Celik, Armangil, Bulbul, Tekgunduz, Oncel, Tuzun, Ergenekon, Ergin, Arsan and Turkish Neonatal Society INTERPDA Study Group. This is an open-access article distributed under the terms of the Creative Commons Attribution License (CC BY). The use, distribution or reproduction in other forums is permitted, provided the original author(s) and the copyright owner(s) are credited and that the original publication in this journal is cited, in accordance with accepted academic practice. No use, distribution or reproduction is permitted which does not comply with these terms. 